\title{
Cytidine deaminase $435 C>T$ polymorphism relates to gemcitabine-platinum efficacy and hematological toxicity in Chinese non-small-cell lung cancer patients
}

\begin{abstract}
Lili $\mathrm{HU}^{1, *}$, Xintong MAO ${ }^{2, *}$, Chao $\mathrm{GAO}^{3}$, Yinhai XU ${ }^{4}$, Chenglin $\mathrm{LI}^{5}$, Tao WANG ${ }^{1}$, Dongmei $\mathrm{LV}^{1, *}$
${ }^{1}$ Department of Pharmacy, The Affiliated Hospital of Xuzhou Medical University; Clinical College, Xuzhou Medical University, Xuzhou, China; ${ }^{2}$ College of Pharmacy, Xuzhou Medical University, Xuzhou, China; ${ }^{3}$ Department of Oncology, The Affiliated Hospital of Xuzhou Medical University, Xuzhou, China; ${ }^{4}$ Department of Medical Laboratory, The Affiliated Hospital of Xuzhou Medical University, Xuzhou, China; ${ }^{5}$ Jiangsu Key Laboratory of New Drug Research and Clinical Pharmacy, Jiangsu Center for the Collaboration and Innovation of Cancer Biotherapy, Xuzhou Medical University, Xuzhou, China
\end{abstract}

${ }^{*}$ Correspondence: dongmeilv1@126.com

${ }^{*}$ Contributed equally to this work.

Received November 16, 2020 / Accepted January 29, 2021

\begin{abstract}
$C D A 435 C>T$ is reported as a functional SNP but there is no relevant research on the efficacy/hematological toxicity of gemcitabine-platinum treatment in Chinese non-small-cell lung cancer (NSCLC) patients. In this study, 63 patients who received radical resection (stage IB or IIIA) and 100 advanced NSCLC (stage IIIB or IV) patients have been collected, and all were treated with gemcitabine-platinum regimens from February of 2017 to February 2019. $C D A 435 C>T$ polymorphisms have been detected by PCR and direct sequencing. CT scan results and blood routine examinations have been collected to evaluate the efficacy and hematological toxicity. Then the relationships have been analyzed about $C D A 435 C>T$. We found that $\mathrm{T}$ allele carriers have better therapy response $(\mathrm{p}<0.05)$. Patients carrying $C D A 435 C / T$ or $T / T$ genotypes are statistically associated with a better efficacy $(\mathrm{p}<0.05)$ but are more prone to leukopenia $(\mathrm{p}<0.05)$. Although there is no difference in grade III-IV hematologic toxicity of 163 patients ( $p>0.05$ ), in the case of 100 stage IIIB-IV patients, the CDA 435C/T and $T / T$ have an increased risk $(\mathrm{p}<0.05)$. Regarding the $C D A 435 C>T$ polymorphism in the Chinese population, in patients with the mutant $\mathrm{T}$ allele, gemcitabine is more effective, but they are more prone to suffering from hematological toxicity, especially the late-stage patients.
\end{abstract}

Key words: NSCLC, gemcitabine, cytidine deaminase, silent mutation, toxicity

Lung cancer as one of the most common malignant tumors causes the leading cancer-related death in the world $[1,2]$. NSCLC accounts for more than $80 \%$ of the total lung cancer, about $57 \%$ of those diagnosed at an advanced stage (stage IIIB-IV), and lost the chance of surgery [3]. Gemcitabine combined with platinum is the first-line chemotherapy regimen for NSCLC [4]. Gemcitabine (2', 2'-difluorodeoxycytidine; dFdC; GEM/Gem) is a synthetic pyrimidine analog with broad-spectrum activity against several solid tumors [5]. Its anti-proliferative function exerts by inhibiting DNA synthesis [6]. The metabolic process is shown in Figure 1.

Polymorphisms of metabolism enzymes and transporters affect both the response and toxicity of gemcitabine $[7,8]$. As the key metabolism enzyme, cytidine deaminase (CDA) is responsible for the inactivation of $90 \%$ of gemcitabine
[9]. Many single nucleotide polymorphisms (SNPs) in the $C D A$-encoding gene have been confirmed to associate with the in vitro activity and clinical outcome of gemcitabine, such as SNPs showed in National Center for Biotechnology Information (NCBI) SNP database: CDA 79A $>C$ (rs2072671, Lys27Gln), CDA 208G $>A$ (rs60369023, Ala70Thr,) and $C D A \quad 435 C>T$ (rs1048977, Thr145Thr), etc.; the CDA $435 C>T$, located on exon 4 of GRCh38.p12 (position, chr 1: 20618562). One clinical study in Caucasians shows that the $C D A 79 A>C / 435 C>T$ polymorphisms influenced the CDA activity and clinical outcome in NSCLC patients [10]. Another study with 192 Caucasian patients reports that the $C D A 435 T / T$ genotype is a better response and associates with a significant risk of non-hematological toxicity of grade $\geq \otimes[11]$. For Asians, the specific CDA 208G $>A$ polymorphism is particular that associates with gemcitabine pharma- 
cokinetics, and the emergence of hematologic toxicity subsequently [12-14]. A study with only 53 Asian NSCLC patients (not Chinese) has researched $C D A 435 C>T$ variants [15]. It is known that drug reaction varies between races $[16,17]$. In Chinese patients, a study of $C D A 435 C>T$ polymorphism is still lacking, especially in the clinical prompt observation that is important in the detection and treatment of adverse drug reactions. In this study, we will verify the relationship between $C D A \quad 435 C>T$ polymorphism and gemcitabine efficacy/hematological toxicity, to provide a foundation for clinical individualized medication.

\section{Patients and methods}

Subjects. In the Chinese Huaihai regional population, a total of 163 Chinese NSCLC patients were recruited in the Affiliated Hospital of Xuzhou Medical University from February 2017 to February 2019. Among them, 63 patients (TNM clinical stage IB or IIIA, NSCLC) underwent radical resection, while the remaining 100 patients (TNM clinical stage IIIB or IV, NSCLC) were treated with palliative chemotherapy.

All the patients firstly received gemcitabine-platinum chemotherapy, age $>18$ years, with good compliance, not related to each other. Excluded other drugs caused blood toxicity, hematologic disease, radio therapeutics, mental system diseases, severe complications and other exceptional cases. This study was approved by the ethics committee of the Affiliated Hospital of Xuzhou Medical University and all patients provided informed consent before participation.

Treatment. All therapeutic regimens were based on the NCCN recommendation and were not intervened. GP regimen: cisplatin/gemcitabine regimens $\left(25 \mathrm{mg} / \mathrm{m}^{2}\right.$ of cisplatin infused over 60 minutes on days $1-3$, plus $1000 \mathrm{mg} / \mathrm{m}^{2}$ of gemcitabine administered intravenously over 30 minutes on days 1 and 8); GN regimen: nedaplatin/gemcitabine regimens $\left(30 \mathrm{mg} / \mathrm{m}^{2}\right.$ of nedaplatin infused over 60 minutes on day $1-3$, plus $1000 \mathrm{mg} / \mathrm{m}^{2}$ of gemcitabine administered intrave- nously over 30 minutes on days 1 and 8). Both regimens were repeated every 3 weeks. All patients were treated at least for four to six cycles.

Evaluation criteria. Patient's information was recorded and evaluated prior to chemotherapy, including: gender, age, body mass index (BMI), histology, medical history, physical examination. The efficacy was evaluated by CT scans every 2 cycles of chemotherapy, then assessed using RECIST 1.1 criteria [18], which divided them into complete response (CR), partial response (PR), stable disease (SD), and progressive disease $(\mathrm{PD})$. The objective response rate (ORR) was calculated with $\mathrm{CR}$ and $\mathrm{PR}$, and the disease control rate (DCR) was calculated with CR, PR, and SD. Correlation between the efficacy and polymorphism was analyzed in 100 patients with measurable focus.

Blood routine examination was recorded on days 1 and 8 of each treatment cycle. Hematological toxicity was assessed using CTCAE 4.0 version [19] and mainly contains: leukopenia, thrombopenia, and aglobulia (Supplementary Table S1), and was analyzed in all 163 and advanced 100 patients separately. If one of them was in compliance with degree III or IV, it might be considered as a serious level.

Genotypes. Genomic DNA was extracted by a DNA extraction kit (Baio Technology, Shanghai, China) from $5 \mathrm{ml}$ of patient's whole blood. The target fragment of $C D A 435 C>T$ gene was $323 \mathrm{bp}$ in length, amplified with PCR: forward primer: GTCTCTCACGCCAGCTTTGC; reverse primer: CCCAAGGCAGGTTGCTAGGA, (synthesized by Sangon Biotech, Shanghai, China). The PCR amplification condition was as follows: denaturation for $5 \mathrm{~min}$, and then $94{ }^{\circ} \mathrm{C}$ for $30 \mathrm{~s}$, annealing at $60^{\circ} \mathrm{C}$ for $30 \mathrm{~s}$, extend at $72^{\circ} \mathrm{C}$ for $40 \mathrm{~s}$ (35 cycles), followed by $72^{\circ} \mathrm{C}$ for $10 \mathrm{~min}$ (ABI 2720, America Applied Biosystems company). Then the fragments verified by electrophoresis were purified and sequenced using ABI 3730 Sequence Detection System (Sangon Biotech Shanghai Co Ltd, Shanghai, America). The CDA 435C $>T$ genotypes were verified by Chromas MFC Application 2.22 comparison software (Technelysium Pty Ltd, South Brisbane, Australia)

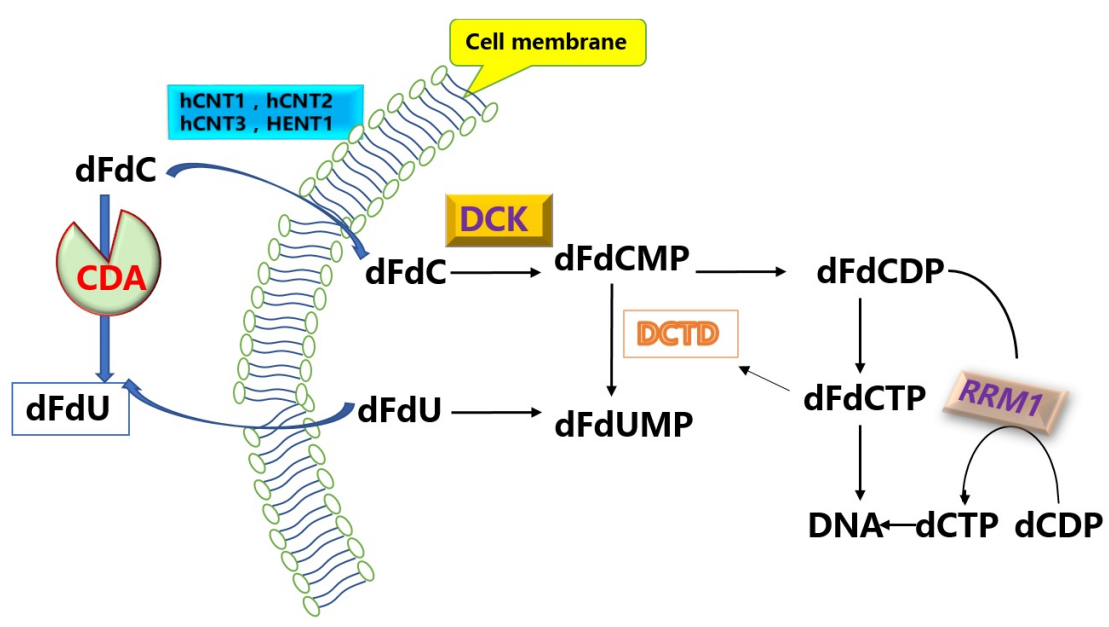

Figure 1. Gemcitabine metabolic processes in vivo. Abbreviations: CDA-drug inactivation; DCK-deoxidization cytidine kinase, drugmetabolizing enzyme; DCTD-deoxidization cytidine monophosphate acid deaminase; RRM1-nucleotide reductase, drug target enzyme; DFdCMP-gemcitabine a phosphate; DFdCDP-gemcitabine diphosphate; DFdCTPgemcitabine triphosphate; DCDP-DNA cell pyrimidine nucleoside diphosphate; DCTPdeoxidization cytidine triphosphate Notes: dFdCDP and dFdCTP for active products. Drug transporters: hCNT1; hCNT2; hCNT3; HENT1. 
(Supplementary Figure $\mathrm{S} 1$ ). The $T$ allele is mutant-type, $C D A$ $435 C / T$ and $T / T$ (or $C D A 435 C / T+T / T$ ) represent genotypes with the mutation.

Statistical analysis. Data were analyzed using SPSS software 20.0 (SPSS Inc. Chicago, IL), figures were made by Power Point 2010 (Microsoft Inc, Washington, USA) and GraphPad Prism software 7.0 (GraphPad Inc, San Diego, CA, USA). One-way ANOVA was used for comparison of multiple mean values, such as age, BMI, etc. Histology was analyzed by Fisher's Exact Test. Hardy-Weinberg test used the Chi-square test to analyze the genetic balance. Pearson's $\chi^{2}$ test was employed to analyze the correlation between genotypes and the efficacy/hematological toxicity.

If the genotype frequency was lower or their responses were common, may be combined. Mean \pm standard devia- tion and percent (\%) represent data. Statistical significance was set at $\mathrm{p}<0.05$.

\section{Results}

Baseline characteristics. In all 163 NSCLC patients, no significant correlations were detected with age, gender, BMI, or clinical stage, and no correlations were found between genotypes and tumor histology, similarly in 100 patients ( $p>0.05$, Table 1). Comprised clinical characteristics between GN and GP regimens, there are also no differences in age, gender, BMI, and histology among 100 and 163 patients ( $>0.05$, Table 2).

The CDA 435C $>T$ genotypes in 163 patients: 86 wild-type genotype $C / C$ cases, 52.8\%; 69 heterozygosity $C / T$ cases,

Table 1. Clinical characteristics of 163 and 100 NSCLC patients with different $C D A 435 C>T$ genotypes.

\begin{tabular}{|c|c|c|c|c|c|c|c|c|}
\hline \multirow[b]{2}{*}{ Characteristic } & \multicolumn{3}{|c|}{ Genotype $(n=163)(\bar{\chi} \pm s, n, \%)$} & \multirow[b]{2}{*}{ p-value } & \multicolumn{3}{|c|}{ Genotype $(n=100)(\bar{\chi} \pm s, n, \%)$} & \multirow[b]{2}{*}{ p-value } \\
\hline & $\begin{array}{c}C / C \\
(\mathrm{n}=86)\end{array}$ & $\begin{array}{c}C / T+T / T \dagger \\
(\mathrm{n}=77)\end{array}$ & $\begin{array}{c}C / T \\
(n=69)\end{array}$ & & $\begin{array}{c}C / C \\
(\mathrm{n}=55)\end{array}$ & $\begin{array}{c}C / T+T / T^{*} \\
(\mathrm{n}=45)\end{array}$ & $\begin{array}{c}C / T \\
(n=41)\end{array}$ & \\
\hline Age (years) & $63.19 \pm 7.56$ & $61.69 \pm 7.96$ & $61.38 \pm 8.09$ & $>0.05$ & $61.53 \pm 7.38$ & $63.20 \pm 8.05$ & $62.68 \pm 8.16$ & $>0.05$ \\
\hline BMI $\left(\mathrm{kg} \cdot \mathrm{m}^{-2}\right)$ & $23.16 \pm 2.74$ & $23.10 \pm 3.10$ & $22.99 \pm 3.04$ & $>0.05$ & $23.11 \pm 2.87$ & $23.05 \pm 3.27$ & $22.90 \pm 3.08$ & $>0.05$ \\
\hline \multicolumn{9}{|l|}{ Gender } \\
\hline Male & $70(81.40)$ & $64(74.42)$ & $56(81.16)$ & \multirow{2}{*}{$>0.05$} & $42(76.36)$ & $35(84.44)$ & $31(75.61)$ & \multirow{2}{*}{$>0.05$} \\
\hline Female & $16(18.60)$ & $13(15.12)$ & $13(18.84)$ & & $13(23.64)$ & $10(22.22)$ & $10(24.39)$ & \\
\hline \multicolumn{9}{|l|}{ Histology } \\
\hline Squamous & $75(87.21)$ & $60(77.92)$ & $53(76.81)$ & \multirow{3}{*}{$>0.05$} & $48(87.27)$ & $38(84.44)$ & $35(85.36)$ & \multirow{3}{*}{$>0.05$} \\
\hline Adenocarcinoma & $9(10.47)$ & $14(18.18)$ & $13(18.84)$ & & $5(9.09)$ & $6(13.33)$ & $5(12.20)$ & \\
\hline Other histology & $2(2.33)$ & $3(3.90)$ & $3(4.35)$ & & $2(3.64)$ & $1(2.22)$ & $1(2.44)$ & \\
\hline \multicolumn{9}{|l|}{ Clinical stage } \\
\hline I & $7(8.14)$ & $13(16.88)$ & $10(14.49)$ & \multirow{5}{*}{$>0.05$} & I & I & I & \\
\hline II & $14(16.28)$ & $14(18.18)$ & $13(18.84)$ & & I & I & I & \multirow{4}{*}{$>0.05$} \\
\hline IIIA & $10(11.63)$ & $5(6.50)$ & $5(7.25)$ & & 1 & 1 & I & \\
\hline IIIB & $30(34.88)$ & $28(36.36)$ & $26(37.68)$ & & $30(54.55)$ & $28(62.22)$ & $26(63.41)$ & \\
\hline IV & $25(29.07)$ & $17(22.08)$ & $15(21.74)$ & & $25(45.45)$ & $17(37.78)$ & $15(36.59)$ & \\
\hline \multicolumn{9}{|l|}{ Regimen } \\
\hline GP & $22(25.58)$ & $20(25.97)$ & $18(26.09)$ & \multirow{2}{*}{$>0.05$} & $16(29.09)$ & $14(31.11)$ & $12(29.27)$ & \multirow{2}{*}{$>0.05$} \\
\hline GN & $64(74.42)$ & $57(74.03)$ & $51(73.91)$ & & $39(70.91)$ & $31(68.89)$ & $29(70.73)$ & \\
\hline
\end{tabular}

Notes: $\dagger,{ }^{*}: C T+T T$, carrying at least one allele $T$. In all 163 patient's $T / T$ number is 8 , in 100 advanced is 4 . $T / T$ has been combined with $C / T$.

Table 2. Comparison of clinical characteristics between GN and GP regimens.

\begin{tabular}{|c|c|c|c|c|c|c|}
\hline \multirow[b]{2}{*}{ Characteristic } & \multicolumn{2}{|c|}{100 cases of advanced NSCLC } & \multirow[b]{2}{*}{ p-value } & \multicolumn{2}{|c|}{163 cases of NSCLC } & \multirow[b]{2}{*}{ p-value } \\
\hline & $\begin{array}{c}\text { GP }(\mathbf{n}=30) \\
(\bar{\chi} \pm \mathbf{s}, \mathbf{n}(\%))\end{array}$ & $\begin{array}{l}\text { GN }(\mathbf{n}=70) \\
(\bar{\chi} \pm s, n(\%))\end{array}$ & & $\begin{array}{c}\text { GP (n=42) } \\
(\bar{\chi} \pm s, n(\%))\end{array}$ & $\begin{array}{c}\text { GN }(\mathbf{n}=121) \\
(\bar{\chi} \pm s, n(\%))\end{array}$ & \\
\hline Age (years) & $63.37 \pm 7.95$ & $61.81 \pm 7.60$ & 0.95 & $62.88 \pm 8.07$ & $62.34 \pm 7.69$ & 0.88 \\
\hline BMI $\left(\mathrm{kg} \cdot \mathrm{m}^{-2}\right)$ & $28.18 \pm 3.18$ & $22.85 \pm 2.74$ & 0.72 & $23.21 \pm 2.91$ & $22.90 \pm 2.92$ & 0.66 \\
\hline Gender & & & 0.57 & & & 0.81 \\
\hline Male & $22(73.33)$ & $55(78.57)$ & & $34(80.95)$ & $100(82.64)$ & \\
\hline Female & $8(26.67)$ & $15(21.43)$ & & $8(19.05)$ & $21(17.36)$ & \\
\hline Histology & & & 0.17 & & & 0.76 \\
\hline Epidermoid & $23(76.67)$ & $63(90.00)$ & & $34(80.95)$ & $101(83.47)$ & \\
\hline Adenocarcinoma & $5(16.67)$ & $6(8.57)$ & & $6(14.29)$ & $17(14.05)$ & \\
\hline Other histology & $2(6.67)$ & $1(1.43)$ & & $2(4.76)$ & $3(2.48)$ & \\
\hline
\end{tabular}


42.3\%; and 8 homozygote mutant genotype $T / T$ cases, $4.9 \%$ (Supplementary Table S2). The CDA 435C>T genotypes of 163 and 100 NSCLC patients are in accordance with the Hardy-Weinberg genetic balance test ( $p>0.05$, Supplementary Table S3) that indicates good genetic balance and group representation.

Efficacy/hematological toxicity between GP and GN regimens. 30 patients received GP treatment and 70 received GN treatment. The short-term curative effect of the GP regimen $(13.33 \%)$ is slightly lower than that of the GN regimen (17.14\%), but there is no statistical significance ( $p>0.05$, Table 3 ), and hematological toxicity showed no difference ( $p>0.05$, Supplementary Table S4). Among all the 163 patients (42 GP regimens, $121 \mathrm{GN}$ regimens), there was also no significant difference in hematological toxicity ( $p>0.05$, Table 3 ), similarly in grade III-IV hematologic toxicity, not only in 163 (6/42 vs. $16 / 121, \mathrm{p}>0.05)$, but also in 100 advanced patients (5/30 vs. $14 / 70, \mathrm{p}>0.05)$.

$C D A 435 C T$ SNP correlates to ORR, DCR in 100 NSCLC patients. In 100 NSCLC patients (stage IIIB-IV), no significant ORR correlations were observed in the $C D A$ $435 C / T$ versus $435 C / C$ patients $(8 / 41$ vs. $5 / 55, \mathrm{p}=0.140$, Table 4), however, $C D A 435 C / T+T / T$ showed a meaningful better effect when compared with $C D A 435 C / C$ (11/45 vs. $5 / 55, \mathrm{p}<0.05$, Table 4$)$; the $T$ allele showed more effective response than the $C$ allele ( $14 / 49$ vs. $18 / 151, \mathrm{p}<0.05$, Table 4 ). By analyzing the DCR, patients with mutant $\mathrm{T}$ allele (CDA $435 \mathrm{C} / \mathrm{T}+\mathrm{T} / \mathrm{T}$ ) better respond than wild-type $\mathrm{C} / \mathrm{C}$ genotype $(42 / 45$ vs. $38 / 55, \mathrm{p}<0.05)$.

Table 3. Comparison of curative effects and hematological toxicity between GN and GP regimens.

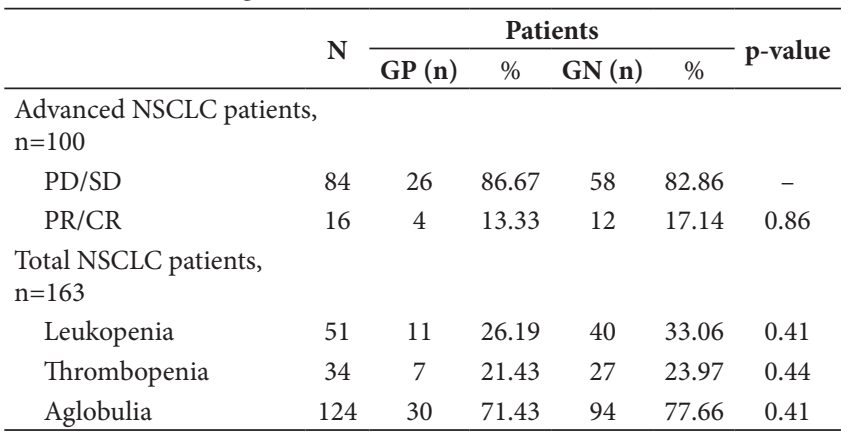

Table 4. Correlation of $C D A 435 C>T$ polymorphisms and the ORR of gemcitabine-platinum in 100 NSCLC patients.

\begin{tabular}{lcccccc}
\hline & Patients, & \multicolumn{2}{c}{ PD/SD $(\mathbf{n}=\mathbf{8 4})$} & \multicolumn{2}{c}{ PR/CR $(\mathbf{n}=\mathbf{1 6})$} & \multirow{2}{*}{ p-value } \\
\cline { 3 - 6 } & $\mathbf{N}$ & $\mathbf{n}$ & $\mathbf{\%}$ & $\mathbf{n}$ & $\mathbf{\%}$ & \\
\hline$C C$ & 55 & 50 & 90.90 & 5 & 9.10 & - \\
$C T$ & 41 & 33 & 80.19 & 8 & 19.51 & 0.14 \\
$C T+T T$ & 45 & 34 & 75.56 & 11 & 24.44 & $0.04^{*}$ \\
$C$ & 151 & 133 & 88.07 & 18 & 11.9 & - \\
$T$ & 49 & 35 & 71.43 & 14 & 28.57 & $0.01^{*}$ \\
\hline Note ${ }^{*} \mathrm{p}<0.05$ & & & & & &
\end{tabular}

$C D A 435 C>T$ SNP correlates to hematologic toxicity in 163 and 100 patients. In a total of 163 patients, the significant leukopenia difference can be seen between CDA 435 $C / T$ and $C / C$ genotype $(p=0.049$, Figure $2 A)$. Similarly, a statistically significant difference between patients with $C D A 435 C / T+T / T$ versus $C / C$ was also observed $(\mathrm{p}=0.046$;

A
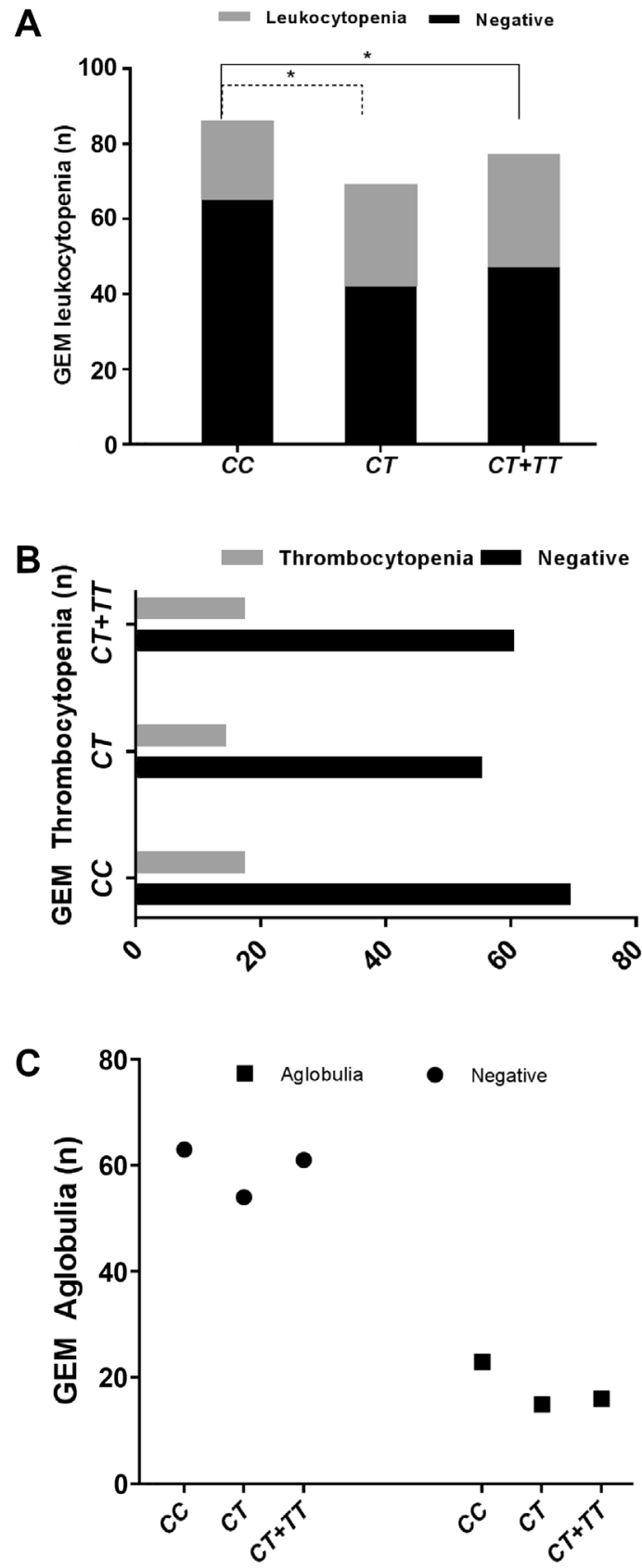

Figure 2. Correlation of $C D A 435 C>T$ polymorphisms and hematologic toxicity in 163 patients. A) $C D A 435 C / T+T / T$ and $C / T$ statistically significantly suffer from leukopenia $(30 / 77$ vs. $21 / 86 ; 27 / 69$ vs. $21 / 86, p<0.05)$. ${ }^{*} p<0.05$. B) No statistical significacet in thrombopenia $(17 / 77,14 / 69$ vs. $17 / 86, p>0.05)$. C) No statistical significance in hemoglobin $(61 / 77,54 / 69$ vs. $63 / 86, p>0.05)$. 
Figure 2A). Elsewise, there were no significant differences in thrombocytopenia and hemoglobin ( $p>0.05$, Figures $2 B, 2 C)$. When we analyzed the grade III-IV hematologic toxicity in 163 patients, no difference was observed ( $p>0.05$, Table 5). However, among 100 stage IIIB or IV patients with grade IIIIV toxicity, worse conditions were observed in CDA 435C/ $T+T / T$ patients $(\mathrm{p}=0.023$, Table 5$)$.

\section{Discussion}

A number of studies evaluated different predictive factors that influence response to current drug therapeutics [20], genetic, and epigenetic alterations occupying an important proportion [21, 22], such as gene mutations, amplification, polymorphic states, or altered gene/protein expression, etc. [23], which was also shown to associate with drug resistance. Among these possible factors, genetic polymorphisms of metabolic enzyme emerged as an attractive target. Because about $90 \%$ of gemcitabine in plasma can be degraded to inactive products by CDA [5], the CDA SNPs have played an important role in gemcitabine activity [24]. Polymorphisms of the CDA gene changing the activity of the CDA may be through the expression and structure of the CDA enzyme, thus transform the chemotherapy effect of gemcitabine [25]. Although $C D A 435 C>T$ alleles don't cause a change in the amino acid, one study shows it could affect CDA function [11]. $C D A 435 C>T$ is an obvious genetic variation [26], the $T$ frequency is 0.26 , which is similar to the T frequency of Asian in Genome Aggregation Database $(\mathrm{T}=0.2556)$ in our study, and we evaluated and proved that $C D A 435 C>T$ polymorphism plays an indispensable function on gemcitabine curative, make up for the data in Chinese NSCLC population [27].

In order to enlarge samples, our data contains two different chemotherapy regimens, GN and GP. The short-term efficacy and hematological toxicity of nedaplatin are comparable to cisplatin in our study, which is consistent with other reports $[28,29]$. Therefore, different platinum has no longer been considered as an influencing factor, so the GN regimen was recruited at the same time. In this study, the real-world cases are selected; those schemes that exist interferences from other treatments and methods have been excluded. A total of 163 cancer patients have been collected, fortunately, they are good group representation and verified the positive conclusion, same in 100 advanced patients.

This study analyses the gemcitabine effect not in 163 but 100 NSCLC patients (stage IIIB-IV), because of measurability lesions. Patients with the $T$ allele ( $C D A 435 C / T+T / T)$ have a better therapeutic response than those carrying the wild-type C genotype. Despite racial differences, these data are partially concordant with one result reported by Ludovini et al. [11]. For Chinese NSCLC patients, the results can provide strong evidence for gemcitabine clinical individualization.

The association between $C D A 435 C>T$ polymorphism and hematologic toxicity has been analyzed in all 163 patients. Patients with $C D A 435 C / T$ and $T / T$ are more prone
Table 5. CDA $435 C>T$ polymorphisms correlation of grade III-IV hematological toxicities in 163 and 100 NSCLC patients.

\begin{tabular}{lcccc}
\hline & \multirow{2}{*}{$\begin{array}{c}\text { Patients, } \\
\mathbf{N}\end{array}$} & \multicolumn{2}{c}{$\begin{array}{c}\text { Grade III-IV hematological } \\
\text { toxicities }\end{array}$} & \\
\cline { 2 - 4 } & & Positive n (\%) & Negative n (\%) & \\
\hline \multicolumn{2}{l}{ Total NSCLC patients, $\mathrm{n}=163$} & & & \\
$C C$ & 86 & $8(11.62)$ & $78(88.37)$ & 0.10 \\
$C T+T T$ & 77 & $14(18.18)$ & $63(81.82)$ & \\
Advanced NSCLC patients, $\mathrm{n}=100$ & & \\
$C C$ & 55 & $6(10.90)$ & $49(89.09)$ & $0.02^{*}$ \\
$C T+T T$ & 45 & $13(28.89)$ & $32(71.11)$ & \\
\hline Note: ${ }^{*} \mathrm{p}<0.05$ & & & &
\end{tabular}

to leukopenia. Despite grade III-IV hematologic toxicity is not significant in all 163 NSCLC patients; in 100 advanced patients, the $C D A 435 C / T+T / T$ genotypes significantly increased the risk. It means that advanced patients with mutated $\mathrm{T}$ alleles have a higher incidence of grade III-IV hematologic toxicity. The low physical function of advanced NSCLC patients may be more liable to suffer toxic and side effects after treatment [30]. Meanwhile, the $\mathrm{T}$ allele may reduce the function of $\mathrm{CDA}$ enzymatic activity, increasing gemcitabine concentration, and other aspects, such as RNA editing or protein modification, etc. [31-33]. That needs to be further confirmed.

Our meaningful short-term efficacy and toxicity results can help in predicting the outcome of gemcitabine, especially in advanced NSCLC patients carrying CDA 435C/T+T/T mutant genotypes in the detection of adverse reactions, in order to deal with timely, or guide lower drug dose selection. About long-term efficacy, there is a study in non-Asian patients where $C D A 435 C / C$ and $C / T$ genotype showed a longer OS [10]. In the Chinese population, it still needs to further assess the $C D A 435 C>T$ polymorphism and overall survival (OS)/long-term toxicity.

Supplementary information is available in the online version of the paper.

Acknowledgments: This work was supported by the Jiangsu Pharmaceutical Association-Aosaikang Hospital Pharmacy Fund (grant number A201622); Xuzhou Science and Technology Bureau (Social Development) project (grant number KC16SH046); Jiangsu Research Hospital Society-2020 Precision Medication Project (JY202033).

\section{References}

[1] CHEN W, ZHENG R, BAADE PD, ZHANG S, ZENG H et al. Cancer statistics in China, 2015. CA Cancer J Clin 2016; 66: 115-132. https://doi.org/10.3322/caac. 21338

[2] SIEGEL RL, MILLER KD, JEMAL A. Cancer statistics, 2020. CA Cancer J Clin 2020; 70: 7-30. https://doi.org/10.3322/ caac. 21590 
[3] SANTARPIA M, ROLFO C, PETERS GJ, LEON LG, GIOVANNETTI E. On the pharmacogenetics of non-small cell lung cancer treatment. Expert Opin Drug Metab Toxicol 2016; 12: 307-317. https://doi.org/10.1517/17425255.2016.1 141894

[4] LE CHEVALIER T, SCAGLIOTTI G, NATALE R, DANSON S, ROSELL R et al. Efficacy of gemcitabine plus platinum chemotherapy compared with other platinum containing regimens in advanced non-small-cell lung cancer: a metaanalysis of survival outcomes. Lung Cancer 2005; 47: 69-80. https://doi.org/10.1016/j.lungcan.2004.10.014.

[5] MINI E, NOBILI S, CACIAGLI B, LANDINI I, MAZZEI T. Cellular pharmacology of gemcitabine. Ann Oncol 2006; 17: v7-12. https://doi.org/10.1093/annonc/mdj941

[6] EVRARD A, LACARELLE B, CICCOLINI J. Severe or lethal toxicities with nucleosides analogs: time for action. Pharmacogenomics 2013; 14: 227-230. https://doi.org/10.2217/ pgs.12.208

[7] OKAZAKI T, JAVLE M, TANAKA M, ABBRUZZESE JL, LI D. Single nucleotide polymorphisms of gemcitabine metabolic genes and pancreatic cancer survival and drug toxicity. Clin Cancer Res 2010; 16: 320-329. https://doi. org/10.1158/1078-0432.CCR-09-1555

[8] TANAKA M, JAVLE M, DONG X, ENG C, ABBRUZZESE JL et al. Gemcitabine metabolic and transporter gene polymorphisms are associated with drug toxicity and efficacy in patients with locally advanced pancreatic cancer. Cancer 2010; 116: 5325-5335. https://doi.org/10.1002/cncr.25282

[9] FARRELL JJ, BAE K, WONG J, GUHA C, DICKER AP et al. Cytidine deaminase single-nucleotide polymorphism is predictive of toxicity from gemcitabine in patients with pancreatic cancer: RTOG 9704. Pharmacogenomics J, 2012; 12: 395-403. Cytidine deaminase single-nucleotide polymorphism is predictive of toxicity from gemcitabine in patients with pancreatic cancer: RTOG 9704.

[10] TIBALDI C, GIOVANNETTI E, TISEO M, LEON LG, D'INCECCO A et al. Correlation of cytidine deaminase polymorphisms and activity with clinical outcome in gemcitabine-/platinum-treated advanced non-small-cell lung cancer patients. Ann Oncol 2012; 23: 670-677. https://doi. org/10.1093/annonc/mdr280

[11] LUDOVINI V, FLORIANI I, PISTOLA L, MINOTTI V, MEACCI $\mathrm{M}$ et al. Association of cytidine deaminase and xeroderma pigmentosum group $\mathrm{D}$ polymorphisms with response, toxicity, and survival in cisplatin/gemcitabinetreated advanced non-small cell lung cancer patients. J Thorac Oncol 2011; 6: 2018-2026. https://doi.org/10.1097/ JTO.0b013e3182307e1f

[12] SUGIYAMA E, KANIWA N, KIM SR, HASEGAWA R, SAITO Y et al. Population pharmacokinetics of gemcitabine and its metabolite in Japanese cancer patients: impact of genetic polymorphisms. Clin Pharmacokinet 2010; 49: 549558. https://doi.org/10.2165/11532970-000000000-00000

[13] SUGIYAMA E, KANIWA N, KIM SR, KIKURA-HANAJIRI R, HASEGAWA R, et al. Pharmacokinetics of gemcitabine in Japanese cancer patients: the impact of a cytidine deaminase polymorphism. J Clin Oncol 2007; 25: 32-42. https://doi. org/10.1200/JCO.2006.06.7405
[14] YONEMORI K, UENO H, OKUSAKA T, YAMAMOTO N, IKEDA $M$ et al. Severe drug toxicity associated with a singlenucleotide polymorphism of the cytidine deaminase gene in a Japanese cancer patient treated with gemcitabine plus cisplatin. Clin Cancer Res 2005; 11: 2620-2624. https://doi. org/10.1158/1078-0432.CCR-04-1497

[15] SOO RA, WANG LZ, NG SS, CHONG PY, YONG WP et al. Distribution of gemcitabine pathway genotypes in ethnic Asians and their association with outcome in non-small cell lung cancer patients. Lung Cancer 2009; 63: 121-127. https:// doi.org/10.1016/j.lungcan.2008.04.010

[16] GANDARA DR, KAWAGUCHI T, CROWLEY J, MOON $J$, FURUSE $\mathrm{K}$ et al. Japanese-US common-arm analysis of paclitaxel plus carboplatin in advanced non-small-cell lung cancer: a model for assessing population-related pharmacogenomics. J Clin Oncol 2009; 27: 3540-3546. https://doi. org/10.1200/JCO.2008.20.8793

[17] WOOD AJ, ZHOU HH. Ethnic differences in drug disposition and responsiveness. Clin Pharmacokinet 1991; 20: 350 373. https://doi.org/10.2165/00003088-199120050-00002

[18] EISENHAUER EA, THERASSE P, BOGAERTS J, SCHWARTZ LH, SARGENT D et al. New response evaluation criteria in solid tumours: revised RECIST guideline (version 1.1). Eur J Cancer 2009; 45: 228-247. https://doi. org/10.1016/j.ejca.2008.10.026

[19] CHEN AP, SETSER A, ANADKAT MJ, COTLIAR J, OLSEN EA et al. Grading dermatologic adverse events of cancer treatments: The Common Terminology Criteria for Adverse Events Version 4.0. J Am Acad Dermatol 2012; 67: 10251039. https://doi.org/10.1016/j.jaad.2012.02.010

[20] CALIFF RM. Biomarker definitions and their applications. Exp Biol Med (Maywood) 2018; 243: 213-221. https://doi. org/10.1177/1535370217750088

[21] MAKINO Y, MAKIHARA-ANDO R, OGAWA T, SATO $\mathrm{H}$, GOTO $\mathrm{Y}$ et al. Individual optimal dose of amrubicin to prevent severe neutropenia in Japanese patients with lung cancer. Cancer Sci 2019; 110: 3573-3583. https://doi. org/10.1111/cas.14194

[22] WONG A, SOO RA, YONG WP, INNOCENTI F. Clinical pharmacology and pharmacogenetics of gemcitabine. Drug Metab Rev 2009; 41: 77-88. https://doi. org/10.1080/03602530902741828

[23] DANESI R, ALTAVILLA G, GIOVANNETTI E, ROSELL R. Pharmacogenomics of gemcitabine in non-small-cell lung cancer and other solid tumors. Pharmacogenomics 2009; 10: 69-80. https://doi.org/10.2217/14622416.10.1.69

[24] CICCOLINI J, DAHAN L, ANDRE N, EVRARD A, DULUC $\mathrm{M}$ et al. Cytidine deaminase residual activity in serum is a predictive marker of early severe toxicities in adults after gemcitabine-based chemotherapies. J Clin Oncol 2010; 28: 160-165. https://doi.org/10.1200/JCO.2009.24.4491

[25] COSTANZI S, VINCENZETTI S, CRISTALLI G, VITA A. Human cytidine deaminase: a three-dimensional homology model of a tetrameric metallo-enzyme inferred from the crystal structure of a distantly related dimeric homologue. J Mol Graph Model 2006; 25: 10-16. https://doi.org/10.1016/j. jmgm.2005.10.008 
[26] CICCOLINI J, SERDJEBI C, PETERS GJ, GIOVANNETTI E. Pharmacokinetics and pharmacogenetics of gemcitabine as a mainstay in adult and pediatric oncology: an EORTCPAMM perspective. Cancer Chemother Pharmacol 2016; 78: 1-12. https://doi.org/10.1007/s00280-016-3003-0

[27] DING X, CHEN W, FAN H, ZHU B. Cytidine deaminase polymorphism predicts toxicity of gemcitabine-based chemotherapy. Gene 2015; 559: 31-37. https://doi.org/10.1016/j. gene.2015.01.010

[28] LIU Y, YU S, LIU S, CAO H, MA R et al. Comparison of nedaplatin-based versus cisplatin-based chemotherapy for advanced non-small cell lung cancer among East Asian populations: A meta-analysis. Sci Rep 2015; 5: 10516. https://doi. org/10.1038/srep10516

[29] SHUKUYA T, YAMANAKA T, SETO T, DAGA H, GOTO K et al. nedaplatin plus docetaxel versus cisplatin plus docetaxel for advanced or relapsed squamous cell carcinoma of the lung (WJOG5208L): a randomized, open-label, phase 3 trial. Lancet Oncol 2015; 16: 1630-1638. https://doi.org/10.1016/ S1470-2045(15)00305-8
[30] LEE G, ZHU M, GE B, POTZOLD S. Widespread expressions of immunoglobulin superfamily proteins in cancer cells. Cancer Immunol Immunother 2012; 61: 89-99. https:// doi.org/ 10.1007/s00262-011-1088-1

[31] JIANG H, ZHANG X, CHEN X, ARAMSANGTIENCHAI P, TONG Z et al. Protein Lipidation: Occurrence, Mechanisms, Biological Functions, and Enabling Technologies. Chemical reviews 2018; 118: 919-988.

[32] LI L, FRIDLEY BL, KALARI K, JENKINS G, BATZLER A et al. Gemcitabine and arabinosylcytosin pharmacogenomics: genome-wide association and drug response biomarkers. PLoS One 2009; 4: e7765. https://doi.org/10.1371/journal. pone. 0007765

[33] SCHVARTZMAN JM, THOMPSON CB, FINLEY LWS. Metabolic regulation of chromatin modifications and gene expression. J Cell Biol 2018; 217: 2247-2259. https://doi. org/10.1083/jcb.201803061 
https://doi.org/10.4149/neo_2021_201116N1229

\section{Cytidine deaminase $435 C>T$ polymorphism relates to gemcitabine-platinum efficacy and hematological toxicity in Chinese non-small-cell lung cancer patients}

Lili $\mathrm{HU}^{1, *}$, Xintong MAO ${ }^{2, *}$, Chao $\mathrm{GAO}^{3}$, Yinhai $\mathrm{XU}^{4}$, Chenglin $\mathrm{LI}^{5}$, Tao WANG ${ }^{1}$, Dongmei $\mathrm{LV}^{1, *}$

\section{Supplementary Information}

Supplementary Table S1. Hardy-Weinberg genetic balance test of 163 and 100 NSCLC patients.

\begin{tabular}{|c|c|c|c|c|c|}
\hline \multirow{2}{*}{ Genotypes } & Actual Frequency & Theoretical Frequency & Actual Frequency & Theoretical Frequency & \multirow{2}{*}{ p-value } \\
\hline & \multicolumn{2}{|c|}{ Patients $n=163(n, \%)$} & \multicolumn{2}{|c|}{ Patients $n=100(n, \%)$} & \\
\hline$C C$ & $86(0.53)$ & $89(0.55)$ & $55(0.55)$ & $57(0.57)$ & \\
\hline$C T$ & $69(0.42)$ & $61(0.38)$ & $41(0.41)$ & $37(0.37)$ & $\mathrm{p}>0.05$ \\
\hline TT & $8(0.05)$ & $11(0.07)$ & $4(0.04)$ & $6(0.06)$ & \\
\hline
\end{tabular}

Supplementary Table S2. Hematological toxicities criteria according to CTCAE 4.0 version.

\begin{tabular}{|c|c|c|c|c|c|}
\hline Hematological toxicities & $\mathbf{I}$ & II & III & IV & $\mathrm{V}$ \\
\hline Leukopenia & $\geq 3.0$ & $<3.0-2.0$ & $<2.0-1.0$ & $<1.0$ & - \\
\hline Thrombopenia & $\geq 75$ & $<75-50$ & $<50-25$ & $<25$ & - \\
\hline Aglobulia & $\geq 100$ & $<100-80$ & $\begin{array}{c}<80 \\
\text { need blood transfusion } \\
\text { treatment }\end{array}$ & $\begin{array}{c}\text { life-threatening } \\
\text { need blood transfusion } \\
\text { treatment }\end{array}$ & death \\
\hline
\end{tabular}

Supplementary Table S3. $C D A 435 C>T$ genotypic and allelic frequencies in 163 NSCLC patients.

\begin{tabular}{lcc}
\hline Genotype & n (\%) & Allelic Frequencies \\
\hline$C D A 435 C>T$ & & $C 0.74 ; T 0.26$ \\
$C / C$ & $86(52.76)$ & \\
$C / T$ & $69(42.33)$ & \\
$T / T$ & $8(4.91)$ & \\
\hline
\end{tabular}

Supplementary Table S4. Comparison of hematological toxicity between GN and GP regimen of 100 NSCLC patients.

\begin{tabular}{lccccc}
\hline \multirow{2}{*}{$\begin{array}{l}\text { Hematological } \\
\text { toxicity }\end{array}$} & \multicolumn{2}{c}{$\mathbf{G P}(\mathbf{n}=\mathbf{3 0})$} & \multicolumn{2}{c}{$\mathbf{G N}(\mathbf{n}=\mathbf{7 0})$} & \multirow{2}{*}{ p-value } \\
\cline { 2 - 5 } & $\mathbf{n}$ & $\mathbf{\%}$ & $\mathbf{n}$ & $\mathbf{\%}$ & \\
\hline Leukopenia & 8 & 26.67 & 27 & 38.57 & 0.25 \\
Thrombopenia & 4 & 13.33 & 19 & 27.14 & 0.21 \\
Aglobulia & 22 & 73.33 & 58 & 82.86 & 0.27 \\
\hline
\end{tabular}
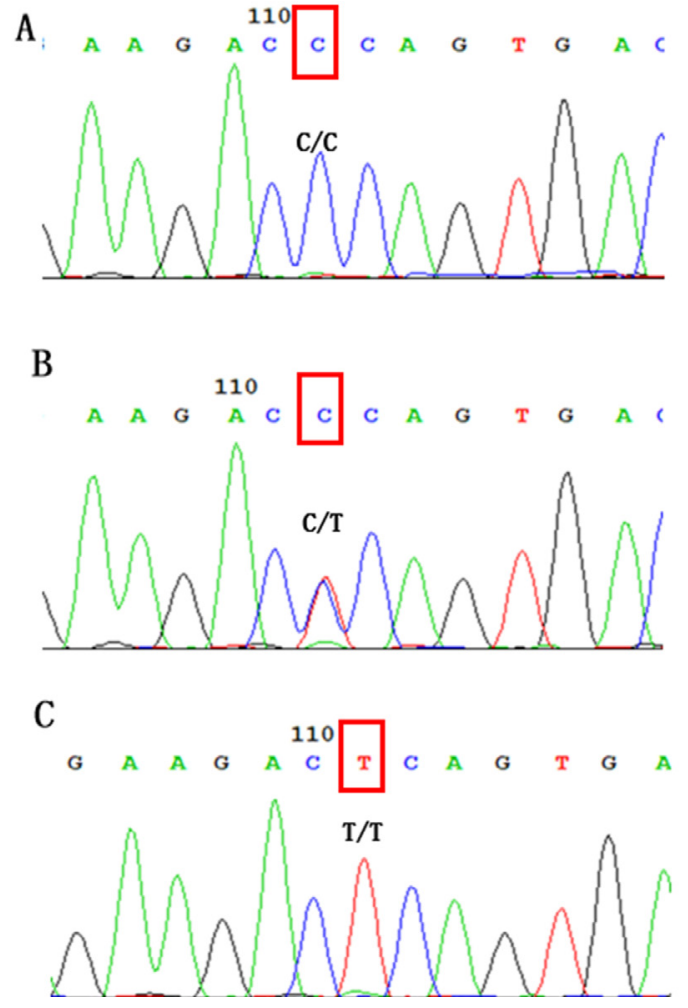

Supplementary Figure S1. CDA 435C $>$ T sequence determination. A) wild-type genotype $C D A 435 C / C$; B) homozygote mutant genotype $C D A$ $435 \mathrm{C} / \mathrm{T}$; C) homozygote mutant genotype CDA 435T/T. 